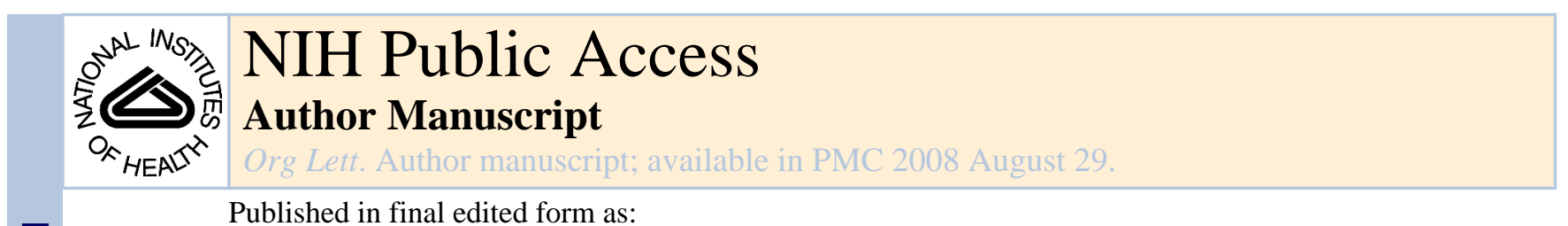

Published in final edited form as:

Org Lett. 2006 September 14; 8(19): 4339-4342. doi:10.1021/ol061683b.

\title{
A Stereoselective Synthesis of Digitoxin and Digitoxigen Monoand Bisdigitoxoside from Digitoxigenin via a Palladium Catalyzed Glycosylation
}

\author{
Maoquan Zhou and George A. O'Doherty \\ Department of Chemistry, West Virginia University, Morgantown, WV 26506
}

\begin{abstract}

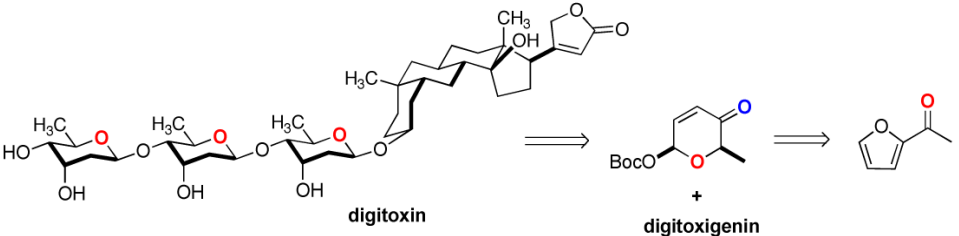

A convergent and stereocontrolled route to trisaccharide natural product digitoxin has been developed. The route is amenable to the preparation of both the digitoxigen mono-and bisdigitoxoside. This route featured the iterative application of the palladium catalyzed glycosylation reaction, reductive 1,3-transposition, diastereoselective dihydroxylation and regioselective protection. The natural product digitoxin was fashioned in 15 steps starting from digitoxigenin 2 and pyranone 8 a or 18 steps from achiral acylfuran.
\end{abstract}

Oligosaccharides bearing deoxysugars have played a pivotal role in many pharmacologically important antibiotics, vaccines and antitumor agents. ${ }^{1}$ The cardiac glycoside digitoxin (1) (Figure 1), which possesses both potent cardiac ${ }^{2}$ and anticancer activities, ${ }^{3}$ is the combination of two natural products, the aglycon digitoxigenin $(2)^{4}$ and the trisaccharide digoxose (3). 5 Recently, Thorson has constructed a neoglycoside library of digitoxin analogues with improved anticancer activity yet lower cardiotoxicity. ${ }^{6}$ To delineate the pharmalogical role the tris-2deoxy sugar plays in the biological activity of digitoxin, synthetic access to digitoxin and its bis-and mono-saccharide analogues are desired.

There have been two syntheses of digitoxin (1), a carbohydrate approach by Wiesner ( $\sim 20$ steps from a protected 2-deoxy sugar) and a de novo approach by McDonald (20 steps from TMS-acetylene). ${ }^{7}$ We planned to prepare digitoxin (1) via a de novo strategy, which could also be used to prepare various digitoxin analogues. Our goal was to design a more efficient route in terms of number of steps and stereocontrol than the previous approaches. ${ }^{8}$

The stereocontrolled synthesis of 2-deoxy sugars is not a problem readily solved by traditional carbohydrate methods. ${ }^{9}$ The deoxymonosaccharides are not naturally abundant or readily available. They are usually prepared from common sugar in multiple steps. The control of anomeric stereochemistry in the installation of 2-deoxyglycosides is also challenging. Due to

George.ODoherty@mail.wvu.edu.

Supporting Information Available: Experimental procedures and spectral data for all new compounds can be found inthe Supporting Information. This material is available free of charge via the Internet at http://pubs.acs.org. 
the missing control element at the 2-position, it is particularly difficult to synthesize $\beta$-2-deoxyglycosides. ${ }^{10}$ This problem was evident in the previous syntheses of digitoxin. 8,11 Herein we describe our successful de novo approach to address the 2-deoxy- $\beta$-glycosides using a diastereoselective palladium catalyzed glycosylation reaction ${ }^{12}$ and its application to syntheses of $\beta$-1,4-linked oligosaccharide natural product digitoxin (1). Our strategy (Scheme 1) features the iterative use of a $\beta$-selective palladium catalyzed glycosylation reaction, followed by diastereoselective installation of the C-3/C-4 hydroxy groups and regioselective C-3 protection.

Previously, we have shown that acylfurans $\mathbf{9 a} / \mathbf{b}$ can be enantioselectively reduced (Noyori, $>95 \%$ ee $)^{13}$ and diastereoselectively converted into the $\alpha$-Boc-pyranones $\mathbf{1 0 a} / \mathbf{b} .{ }^{14}$

Alternatively, the $\beta$-pyranones $\mathbf{8 a} / \mathbf{b}$ can be isolated in a $\sim 50 \%$ yields after chromatographic separation. If the Boc-protection is performed at elevated temperature $\left((\mathrm{Boc})_{2} \mathrm{O} / \mathrm{NaOAc}\right.$ in benzene at $\left.80{ }^{\circ} \mathrm{C}\right)$, the pyranones can be prepared as a diastereomeric mixture at the anomeric center (Scheme 2). The ratio of $\beta$-pyranones to $\alpha$-pyranones at these higher temperatures can be as high as 1.3:1. Fortunately, once the $\alpha$-pyranones 10 and $\beta$ pyranones 8 have been separated they can be converted via palladium (0) catalysis into their corresponding mixed acetal pyranones with complete retention of stereochemistry (i.e. 10 to 11 and $\mathbf{8}$ to 12). By means of a palladium catalyzed glycosylation ${ }^{12 \mathrm{a}}$ the $\alpha$-pyranones can be oligomerized and subsequently transformed into alinked oligosaccharides. ${ }^{12 \mathrm{~d}}$ Encouraged by these results, we decided to investigate the use of the $\beta$-isomers $\mathbf{8} \mathbf{a} / \mathbf{b}$ for the synthesis of $\beta$-linked oligosaccharides (e.g. digitoxin 1).

Our initial effort towards the preparation of 2-deoxysugars commenced with the synthesis of the 2-deoxy-L-allose. Thus using only $5 \mathrm{~mol} \%$ palladium, the $\beta$ pyranone ent-8b ${ }^{14}$ was coupled with benzyl alcohol providing $\beta$-benzyloxy pyranone 13 in $84 \%$ yield (Scheme 3 ). A reduction of pyranone 13 under Luche conditions ${ }^{15}$ gave a mixture allylic alcohols $14 \mathbf{a} / \mathbf{b}$ in $88 \%$ yield with the diastereomeric ratio of ca. 1.5 to 1 . The diastereomeric ratio of alcohols could be improved with the use of DibalH ( $\mathrm{dr}=6: 1)$, albeit in slightly lower yields. Fortunately, we were able to use both diastereomers of $\mathbf{1 4} \mathbf{a} / \mathbf{b}$ in the subsequent reaction, which allowed us to use the operational simpler $\mathrm{NaBH}_{4}$ procedure. Thus, exposing the mixture of allylic alcohols $\mathbf{1 4} / \mathbf{a} \mathbf{b}$ to the Myers' reductive rearrangement conditions ${ }^{16}\left(\mathrm{NBSH}, \mathrm{PPh}_{3} \mathrm{DEAD}, \mathrm{NMM},-30\right.$ ${ }^{\circ} \mathrm{C}$ to $\mathrm{rt}$ ) provided olefin $\mathbf{1 5}$ in $\mathbf{7 1 \%}$ yield. Dihydroxylation of $\mathbf{1 5}$ using the Upjohn conditions ${ }^{17}\left(\mathrm{OsO}_{4} / \mathrm{NMO}\right)$ gave exclusively the diol 16 in $91 \%$ yield. While this seven step sequence to 2 -deoxy- $\beta$-allose from acylfuran $9 \mathbf{b}$ incorporates two non-selective steps, all the post-glycosylation steps (13 to $\mathbf{1 6}$ ) lead to a single diastereomeric product.

With the promising results of the synthesis of 2-deoxy-allo-sugar 16, we next investigated the synthesis of digitoxin using the same strategy starting from the digitoxigenin and $\beta$-pyranone 8a Schemes(4-6). Our initial concern about the compatibilities of the tertiary alcohol and furan formation of lactone in the aglycon proved to be superfluous. Thus, both the palladium catalyzed glycosylation and Luche reduction occurred with complete chemoselectivity (i.e. the tertiary alcohol and the butenolide ring of the aglycon were left untouched).

In practice, palladium catalyzed glycosylation of digitoxigenin $\mathbf{2}$ with the pyranone 8a gave the $\beta$-glycoside $\mathbf{1 7}$ as a single diastereomer and in good yield (86\%). Luche reduction of $\mathbf{1 7}$ provided a mixture of allylic alcohols $\mathbf{1 8 a} / \mathbf{b}(90 \%)$, which were inseparable (Scheme 4$)$. Reductive rearrangement of the diastereomeric mixture of allylic alcohols $18 \mathbf{a} / \mathbf{b}$ provided olefin 19 in $80 \%$ yield. Dihydroxylation of 19 using the Upjohn conditions $\left(\mathrm{OsO}_{4} / \mathrm{NMO}\right)$ gave exclusively the digitoxigen monodigitoxoside $\mathbf{2 0}$ in $93 \%$ yield. 18,19

As with all the other post-glycosylation transformation the regioselective acylation of diol 20 proved to be compatible with the aglycon functionality as well as the glycosidic bond. We 
found that simply applying an orthoester formation/hydrolysis protocol to diol $\mathbf{2 0}$ provided the mono-protected sugar $\mathbf{2 1}$ (98\% yield), which is ready for subsequent glycosylation (21 to $\mathbf{2 2}$, Scheme 5). ${ }^{20}$

We next explored the glycosylation of the $C$-4 secondary alcohol in $\mathbf{2 1}$ for the synthesis of disaccharide 26. Thus, subjecting the alcohol $\mathbf{2 1}$ and pyranone 8a to the typical palladium catalyzed glycosylation conditions afforded the $C$-4 glycosylated disaccharide $\mathbf{2 2}$ in $80 \%$ yield with complete stereocontrol at the anomeric center (Scheme 5). Similarly, Luche reduction of the keto-group in pyranone 22 provided a 1.6:1 mixture of allylic alcohols $\mathbf{2 3} \mathbf{a} / \mathbf{b}$, which when exposed to the Myers' reductive 1,3-allylic transposition conditions provided olefin 24 in $82 \%$ yield. Once again, dihydroxylation of $\mathbf{2 4}$ gave exclusively the diol $\mathbf{2 5}$ in $91 \%$ yield. The digitoxigen bisdigitoxoside $\mathbf{2 6}$ was fashioned by deprotection of the acyl-protecting group in 25 ( $82 \%$ yield).

The installation of the final sugar occurred with the same efficiency and high degree of stereocontrol as seen in the conversion of aglycon $\mathbf{2}$ to monosaccharide $\mathbf{2 0}$ and monosaccharide 21 to disaccharide 26 Schemes (4 and 5). Once again, this effort began with a regioselective protection of axial alcohol in diol $\mathbf{2 5}$, which provided 27 in excellent yield (99\%).

Subjecting the alcohol $\mathbf{2 7}$ and pyranone $\mathbf{8 a}$ to our typical $\operatorname{Pd}(0)$-catalyzed glycosylation stereoselectively installed the final pyran ring to fashion the 1,4-linked trisaccharides $\mathbf{2 8}$ in $90 \%$ yield (Scheme 6). A diastereomeric mixture of allylic alcohols $\mathbf{2 9 a} / \mathbf{b}$ was obtained in $98 \%$ yield when enone $\mathbf{2 8}$ underwent Luche reduction. Upon exposure to the Myers reductive rearrangement conditions, both allylic alcohols in $\mathbf{2 9} \mathbf{a} / \mathbf{b}$ reductively rearranged to corresponding olefin $\mathbf{3 0}$ in $89 \%$ yield. The digitoxose trisaccharide $\mathbf{3 1}$ was prepared with high yield and complete stereocontrol by dihydroxylation of olefin in $\mathbf{3 0}$. Finally the natural product digitoxin (1) was prepared by deprotection of the two acetate-protecting groups in $\mathbf{3 1}$, which gave synthetic material $1(83 \%)$ with identical physical and spectral data to that of the commercially available natural product $\mathbf{1}^{21}\left({ }^{1} \mathrm{H}\right.$ NMR, ${ }^{13} \mathrm{C}$ NMR, optical rotation and melting point).

In conclusion, a straightforward and stereocontrolled 15-step route to digitoxin (1) from digitoxigenin (2) as well as corresponding mono-and disaccharides ( $\mathbf{2 0}$ and $\mathbf{2 6}$ ) has been developed. This new route featured the iterative use of the palladium catalyzed $\beta$-glycosylation reaction, Myers' reductive rearrangement, diastereoselective dihydroxylation and regioselective protection. This work not only shows the assembly of the nine stereocenters of the trisaccharide from an achiral starting material, it also demonstrates the functional group compatibility of this approach (e.g. the tertiary alcohol and both the double bond and carbonyl group of the butenolide). This unique application of our Pd-catalyzed glycosylation efficiently prepares a challenging and important 2 -deoxy- $\beta$-glycoside target. This approach is mild and equally amenable to the preparation of various digitoxin analogues. The uses of this strategy for the synthesis of various analogues are ongoing.

\section{Supplementary Material}

Refer to Web version on PubMed Central for supplementary material.

\section{Acknowledgment}

We thank the NIH (GM63150) and NSF (CHE-0415469) for their generous support of our research program. Funding for a $600 \mathrm{MHz}$ NMR and an LTQ-FT Mass Spectrometer by the NSF-EPSCoR (\#0314742) is also gratefully acknowledged. 


\section{References}

1(a). Toshima K, Tatsuta K. Chem. Rev 1993;93:1503-1531. (b) Danishefsky SJ, Bilodeau MT. Angew. Chem., Int. Ed. Engl 1996;35:1380-1419. (c) Kirschning A, Bechthold AF-W, Rohr J. Top. Curr. Chem 1997;188:1-84. (d) Marzabadi CH, Frank RW. Tetrahedron 2000;56:8385-8417. (e) Kirschning A, Jesberger M, Schoning KU. Synthesis 2001:507-540. (f) Nicolaou KC, Mitchell HJ. Angew. Chem. Int. Ed 2001;40:1576-1624. (g) He X, Liu H-W. Annu. Rev. Biochem 2002;71:701754. [PubMed: 12045109]

2. Digitoxin has been used to treat congestive heart failure and cardiac arrhythmia for over 200 years. However, extensive care must be taken when treated with digitoxin because the typical therapeutic dose (14-26 $\left.\mathrm{ng} \mathrm{mL}^{-1}\right)$ is dangerously close to the toxic dose $\left(>35 \mathrm{ng} \mathrm{mL}^{-1}\right)$.

3. Handbook Exp. Pharmacol. 56. 1981. Cardiac Glycosides, Part 1: Experimental Pharmacology.

4(a). For the synthesis of digitoxigenin see: Danieli N, Mazur Y, Sondheimer F. J.Am. Chem. Soc 1962;84:875-876. (b) Donovan SF, Avery MA, McMurry J,E. Tetrahedron Lett 1979;35:3287-90. (c) Tsai TYR, Minta A, Wiesner K. Heterocycles 1979;12:1397-1402. (d) Marini-Bettolo R, Flecker P, Tsai TYR, Wiesner K. Can. J. Chem 1981;59:1403-1410. (e) Kabat, Marek M. J. Org. Chem 1995;60:1823-1827. (f) Stork G, West F, Lee HY, Isaacs RCA, Manabe S. J. Am. Chem. Soc 1996;118:10660-10661. (g) Almirante N, Cerri A. J. Org. Chem 1997;62:3402-3404. [PubMed: 11671729] (f) Bocknack BM, Wang L-C, Krische MJ. Proc. Natl. Acad. Sci 2004;101:5421-5424. [PubMed: 15024093]

5. The attempts at the selective hydrolysis of digitoxin (1) to form digoxose (3) has been futile, only the monosaccharide digitoxose was isolated. Surprisingly, $\mathbf{3}$ can be isolated from the dried twigs of Orthenthera viminea, see: Tiwari KN, Khare NK, Khare A, Khare MP. Carbohydr. Res 1984;129:179_ 187.

6. Langenhan JM, Peters NR, Guzei IA, Hoffmann FM, Thorson JS. Proc. Natl. Acad. Sci 2005;102:12305-12310. [PubMed: 16105948]

7(a). Wiesner K, Tsai TYR, Jin H. Helv. Chim. Acta 1985;68:300-314. (b) Wiesner K, Tsai TYR. Pure Appl. Chem 1986;58:799-810. (c) McDonald FE, Reddy KS, Diaz Y. J. Am. Chem. Soc 2000;122:4304-4309. (d) McDonald FE, Reddy KS. Angew. Chem. Int. Ed 2001;40:3653-3655.

8. In both the Wiesner and McDonald syntheses of digitoxin at least one of the three glycosidic bonds was assembled with poor stereoselectivity, see: ref. 7.

9(a). Roush WR, Bennett CE. J. Am. Chem. Soc 1999;121:3541-3542. (b) Sherry BD, Loy RN, Toste FD. J. Am. Chem. Soc 2004;126:4510-4511. [PubMed: 15070356]

10(a). Toshima K, Tatsuta K. Chem. Rev 1993;93:1503-1531. (b) Roush WR, Lin X-F. J. Am. Chem. Soc 1995;117:2236-2250.

11. In contrast, McDonald is able to use his methodology to prepare an all- $\alpha$-analogue of digitoxin with high stereocontrol, see: McDonald FE, Wu M. Org. Lett 2002;4:3979-3981. [PubMed: 12599507]

12(a). Babu RS, O’Doherty GA. J. Am. Chem. Soc 2003;125:12406-12407. [PubMed: 14531673] (b) Comely AC, Eelkema R, Minnaard AJ, Feringa BL. J. Am. Chem. Soc 2003;125:8714-8715. [PubMed: 12862452] (c) Kim H, Men H, Lee C. J. Am. Chem. Soc 2004;126:1336-1337. [PubMed: 14759180] For its application in the de novo synthesis of $\alpha$-linked 1,4-and 1,6-oligosaccharides, see: (d) Babu RS, Zhou M, O’Doherty GA. J. Am. Chem. Soc 2004;126:3428-3429. [PubMed: 15025462]

13(a). Fujii A, Hashiguchi S, Uematsu N, Ikariya T, Noyori R. J. Am. Chem. Soc 1996;118:2521-2522. (b) Li M, Scott JG, O'Doherty GA. Tetrahedron Lett 2004;45:1005-1009. (c) Li M, O’Doherty GA. Tetrahedron Lett 2004;45:6407-6411.

14(a). Babu RS, O’Doherty GA. J. Carb. Chem 2005;24:169-177. (b) Guo H, O'Doherty GA. Org. Lett 2005;7:3921-3924. [PubMed: 16119932]

15 (a). For reduction of $\beta$-pyranones, the $\mathrm{CeCl}_{3}$ is necessary to avoid 1,4 - reduction products. For Luche reduction, see: Luche JL. J. Am.Chem. Soc 1978;100:2226-2227. (b) Haukaas MH, O’Doherty GA. Org. Lett 2001;3:401-404. [PubMed: 11428024]

16(a). Myers AG, Zheng B. J. Am. Chem. Soc 1996;118:4492-4493. (b) Myers AG, Zheng B. Tetrahedron Lett 1996;37:4841-4844. (c) Myers AG, Zheng B, Movassaghi M. J. Org. Chem 1997;62:7507. [PubMed: 11671877] (d) Haukaas MH, O’Doherty GA. Org. Lett 2002;4:17711774. [PubMed: 12000295] 
17. VanRheenen V, Kelly RC, Cha DY. Tetrahedron Lett 1976;17:1973-1976.

18(a). Mono- and bis-digtoxosides has been prepared by gradual degradation of digitoxin, see: Satoh D, Aoyama K. Chem. Pharm. Bull 1970;18:94-98. (b) Templeton FJ, Setiloane P, Kumar VPS, Yan Y, Zeglam HT, LaBella FS. J. Med. Chem 1991;34:2778-2782. [PubMed: 1895297] Our synthetic material 20 and 26 have identical physical and spectral data with degraded products in the terms of ${ }^{1} \mathrm{H}$ NMR, ${ }^{13} \mathrm{C}$ NMR, optical rotation and melting point.

19. The nomenclature of compounds $\mathbf{2 0}$ and $\mathbf{2 6}$ was used according to ref. 18.

20(a). Acetate protecting group was demonstrated to provide significant stabilization effect for the acidsensitive glycosides. Kunz H, Unverzagt C. Angew. Chem. Int. Ed 1988;27:1697-1699. (b) Unverzagt C, Kunz H. Bioorg. Med. Chem 1994;2:1189-1201. [PubMed: 7757416] (c) McDonald FE, Danishefsky SJ. J. Org. Chem 1992;57:7001-7002.

21. Digitoxin purchased from Acros was used to do the comparison. 


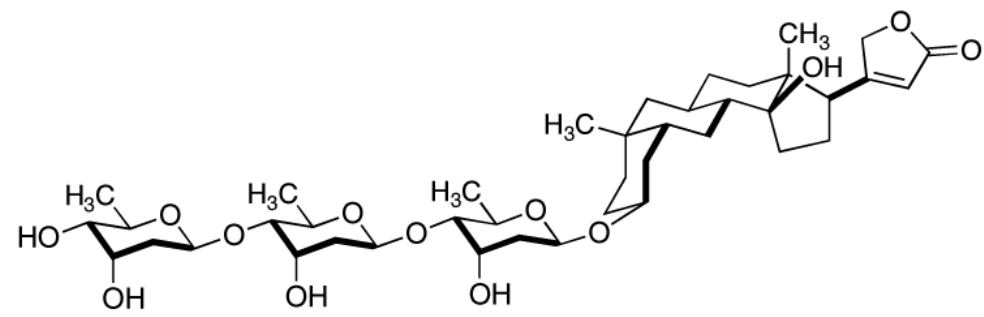

digitoxin (1)
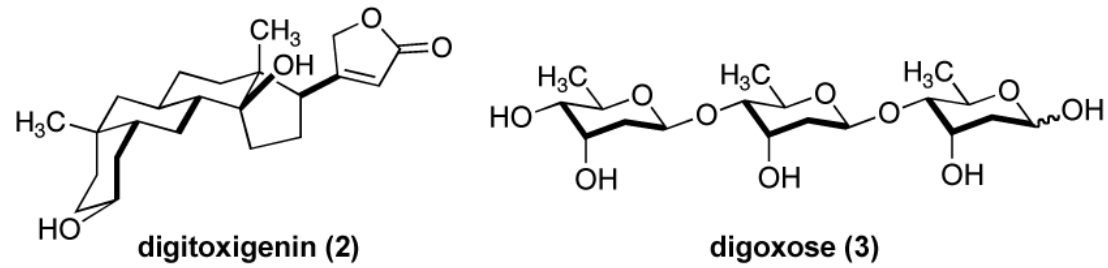

Figure 1.

Digitoxin, digitoxigenin and digoxose 


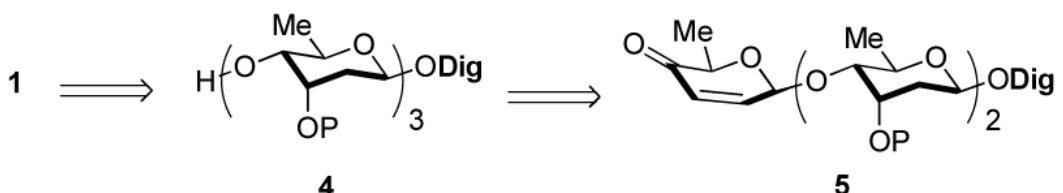

4

5
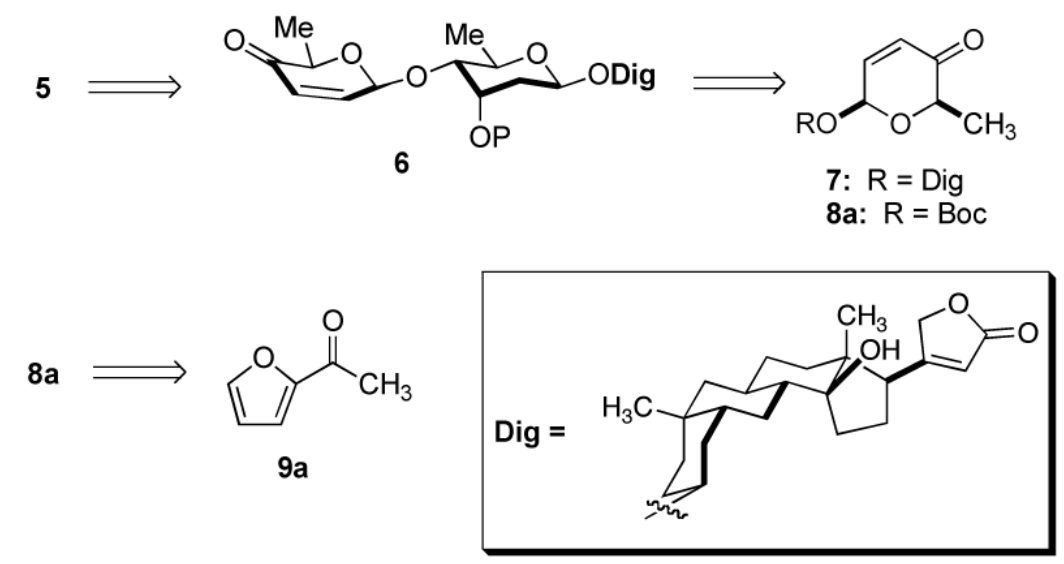

Scheme 1.

Digitoxin retrosynthetic analysis 


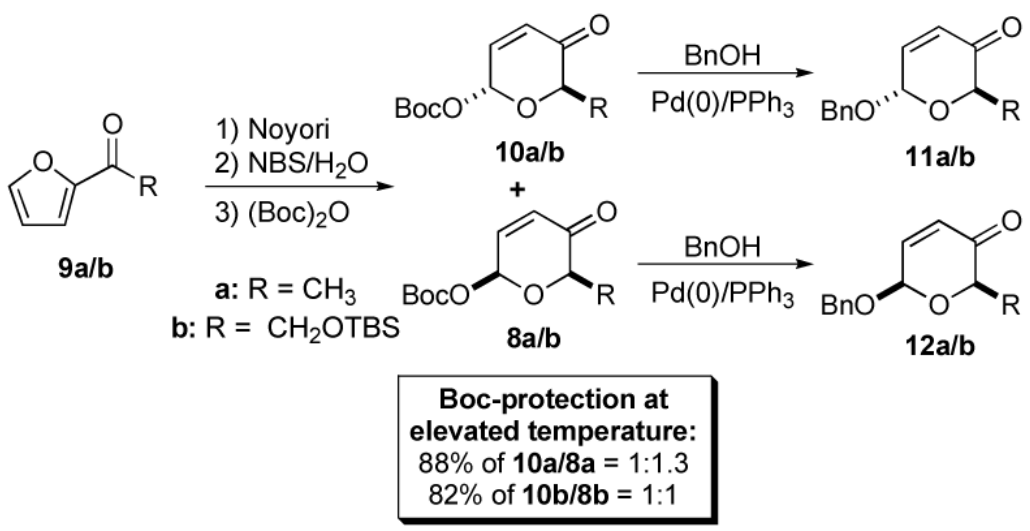

Scheme 2.

Pyranone synthesis 


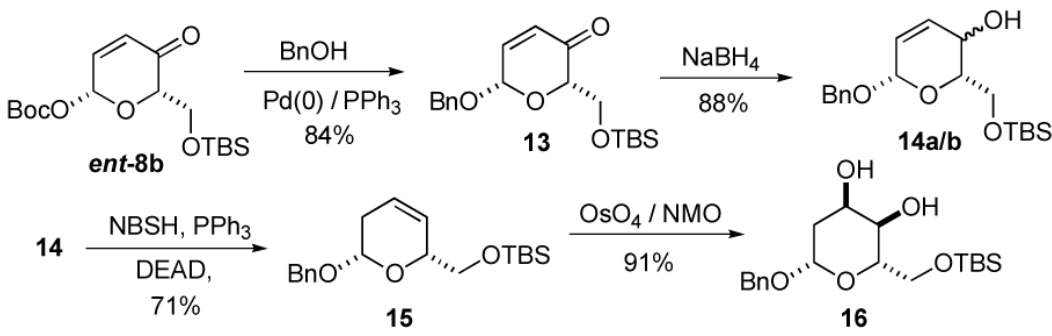

Scheme 3.

Synthesis of 2-deoxy-L-allose 

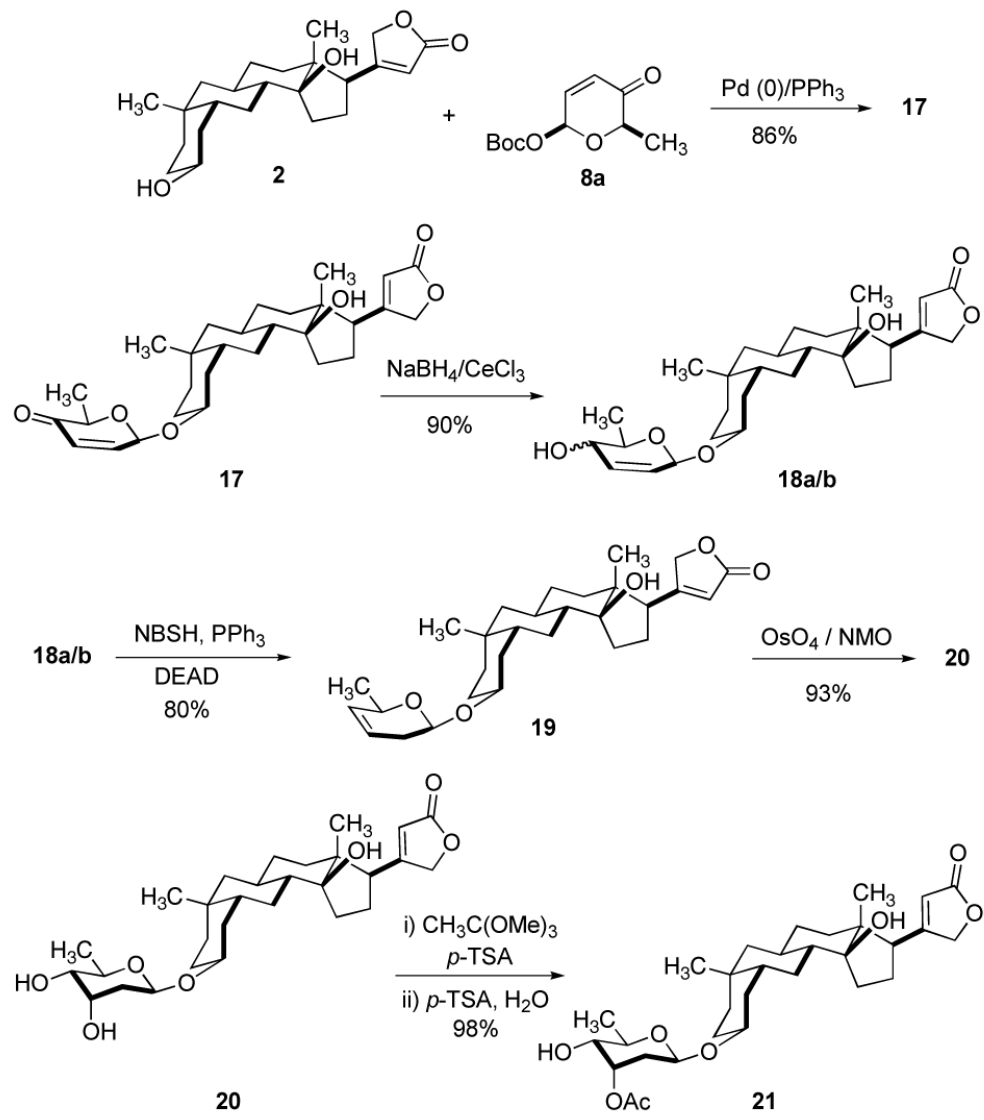

Scheme 4.

Synthesis of digitoxigen monodigitoxoside 


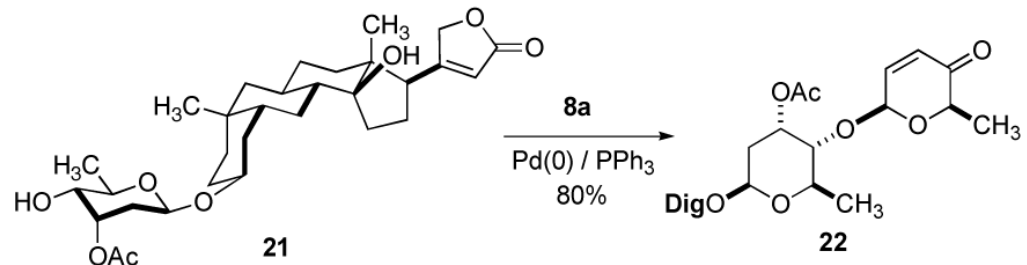

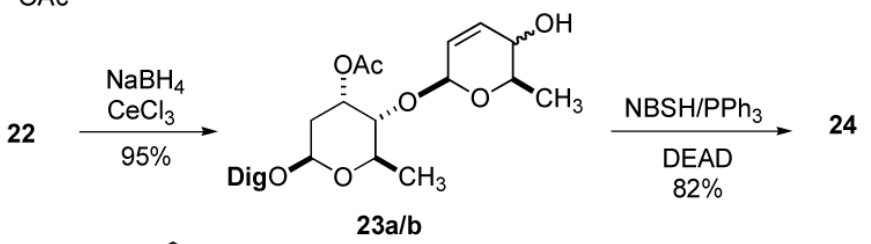

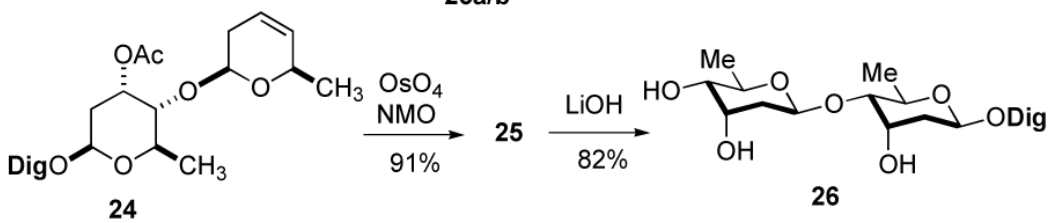

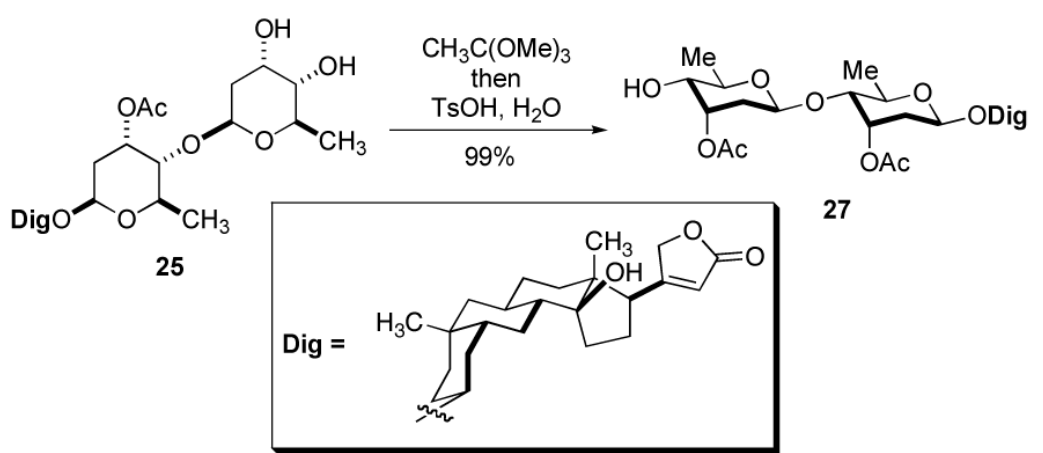

Scheme 5.

Synthesis of digitoxigen bisdigitoxoside 

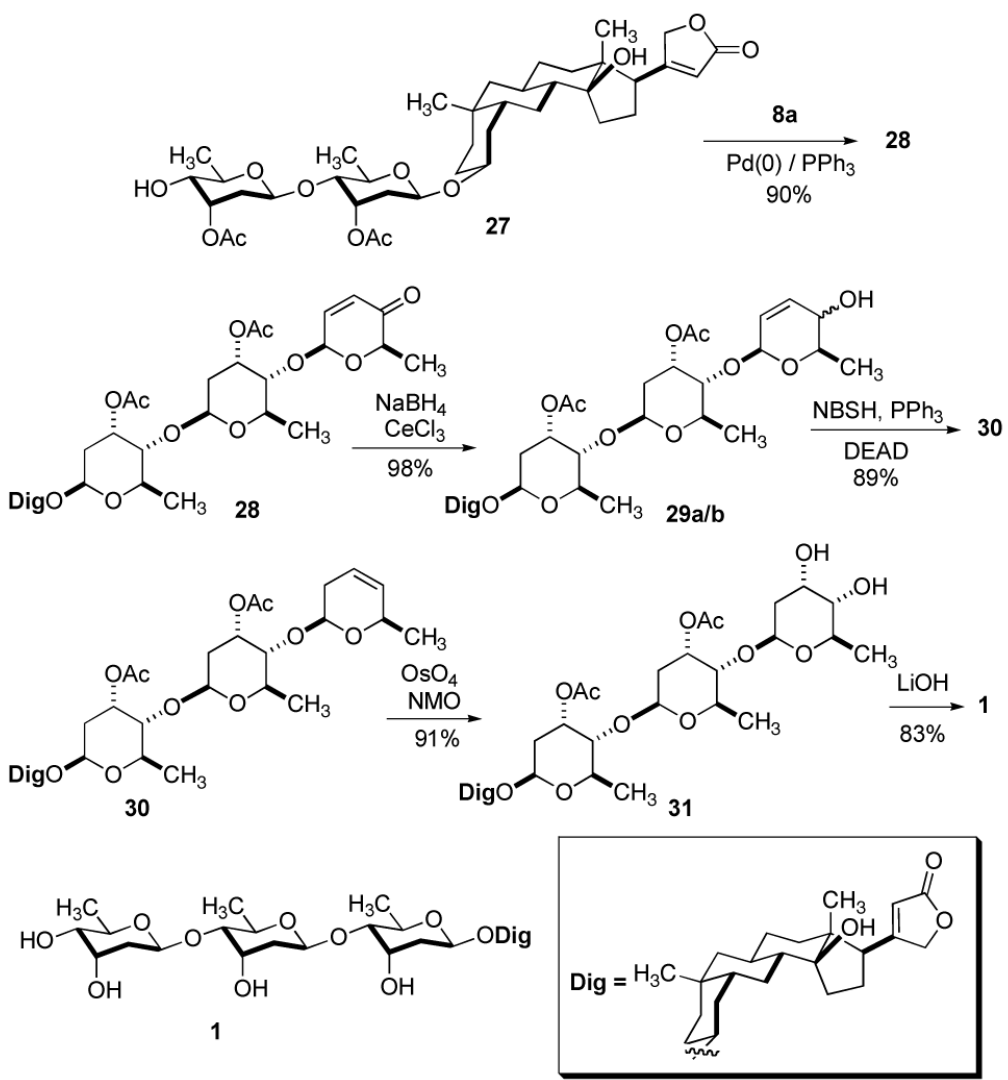

Scheme 6.

Synthesis of digitoxin(1) 